\title{
Young carers and young adult carers in Switzerland: Caring roles, ways into care and the meaning of communication
}

\author{
${ }^{1}$ Agnes Leu \\ Kalaidos University of Applied Sciences, Careum School of Health, Research Department, Zurich, \\ Switzerland \\ University of Basel, Medical Faculty, Institute for Biomedical Ethics, Basel, Switzerland
}

\section{${ }^{2}$ Marianne Frech}

Kalaidos University of Applied Sciences, Careum School of Health, Research Department, Zurich, Switzerland

Department of Nursing Science, Faculty of Social Sciences, University of Vienna

\section{Correspondence}

Marianne Frech, Careum Research, Kalaidos University of Applied Sciences, Department of Health Science, Zurich, Switzerland.

Email: marianne.frech@careum-hochschule.ch

\section{${ }^{3}$ Corinna Jung}

Kalaidos University of Applied Sciences, Careum School of Health, Research Department, Zurich, Switzerland

MSB Medical School Berlin, Hochschule für Gesundheit und Medizin, Department Pädagogik und Soziales, Berlin, Germany 


\title{
Young Carers and Young Adult Carers in Switzerland: Caring Roles, Ways into Care and the Meaning of Communication
}

\begin{abstract}
Although there is now general recognition that many relatives provide unpaid care for family members, there is still little awareness that children, adolescents and young adults under 25 also provide such care. Until recently, the situation of young carers and young adult carers, as those young persons are referred to in international research, has not been the focus of professionals, research and the public in Switzerland.

Between September 2015 and October 2016, 30 interviews were conducted in seven cantons with 16 young carers aged 10 to 17 and 14 young adult carers aged 18 to 25 . The interviews were recorded, transcribed and analysed following a grounded theory approach. This paper now presents the first qualitative data on Swiss young carers and young adult carers. It explores their sociodemographic backgrounds, the nature and intensity of the caring tasks they carry out, and their pathways into caring as well as the role of communication with family members, extended family, professionals and peers. Our findings highlight the actual existence of young carers and young adult carers in Switzerland and illustrate for the first time the challenges they face.
\end{abstract}

Keywords: Young Carers; Young Adult Carers; Communication; Switzerland; Interviews 


\section{Young Carers and Young Adult Carers in Switzerland: Caring Roles, Ways into Care and the Meaning of Communication}

\section{Introduction}

Although there is a general recognition that many relatives provide unpaid care for an ill family member, there is still little awareness, especially in Switzerland, that children and young people also provide such care (Leu \& Becker, 2016, Leu \& Frech, 2015a, 2015b; Leu, Jung, \& Frech, 2016a, 2016b, 2017). These 'young carers', as they are referred to in international research, continue to represent a 'hidden army' of recipients of healthcare and welfare (Banks et al., 2002; Becker, 2007; Becker \& Leu, 2014; Hill, Smyth, Thomson, \& Cass, 2009; Stamatopoulos, 2015). Research from Australia and the UK, for example, provides an opportunity to compare the living situations of children and adolescents who consider themselves to be young carers with those who do not declare a caring role but live with a person in need of assistance. While living with a person who has need of assistance does not automatically imply that a child or adolescent is a young carer, the published research may show similarities (and differences) between those two groups, i.e., the identified and potential young carers (Hill, Smyth, Thomson, \& Cass, 2009). For Switzerland, too, young carers and young adult carers remain mostly unseen. This leads to the fact that even when potential support measures are available, when professionals fail to identify the young carers and young adult carers, they remain hidden (Knowles et al., 2016). This covert nature of caring can have wide impacts on these young people's personal development and on their access to support for themselves as well as for their family (Banks et al., 2002; Becker \& Leu, 2014; Early \& Cushway, 2002; Frank, 1995; Moore, Morrow, McArthur, Noble-Carr, \& Gray, 2006). Governmental as well as non-governmental professional services and professionals in healthcare, education and social services often lack awareness and do not recognise these young people as carers; young carers, equally, seldom identify themselves as such. The failure to identify, however, is a key reason for the lack of support (Cass, Smyth, Hill, Blaxland, \& Hamilton, 2009; Moore \& McArthur, 2007; Morrow, 2005), as we shall also show below. It can occur as a result of non-communication within the family as well as a lack of communication with friends, peers and professionals outside the family 
group. Young carers may think of the support they provide as 'normal' or 'nothing uncommon' and therefore see no need to speak about their responsibilities within the family (Fives, Kennan, Canavan, \& Brady, 2013; Moore \& McArthur, 2007).

In Switzerland, the situation of young carers had not been the focus of professionals, researchers and the public until 2014 when the first national research programme was launched (Leu \& Becker, 2016). Based on international research findings, we started with the hypothesis that children, adolescents and young adults with caring roles were also present in Switzerland. First, we wanted to find young carers and young adult carers and learn more about their lives and caring roles.

This paper now presents the first data on Swiss young carers and young adult carers from this ongoing programme. During the interviews, we collected information on their socio-demographic circumstances, and following the principles of theoretical coding from Strauss' and Corbins' grounded theory (GT) approach, we were able to elaborate several important topics from the interviews that are presented below, including the kind and number of caring tasks they carry out as well as their pathways into caring. Our findings highlight their existence in Switzerland and the importance of communication, which is crucial to prevent isolation and enable access to support through recognition and provision of information to professionals.

\section{Methods}

The findings presented here were collected in a major new research programme that explores the lives of young carers in Switzerland using a multi-methods approach (a summary of the project is shown in Table 1). In this first study, we have selected a qualitative approach in order to gain a deeper insight into the lives of our target group.

Table 1

\section{Ethics approval}

The project was presented to the ethics committee Zurich in the form of a comprehensive ethics application. The ethics committee Zurich declared a clearance certificate (Nr. 29-2015). 


\section{Field access}

We recruited participants with the support of gatekeepers from healthcare services, schools and schoolbased social workers, social services and NGOs working with specific illness types (including palliative care associations, home care nursing services, and others). In all the selected cantons, we applied an identical recruitment strategy (see below). As shown by international research findings, access to this 'hidden' population is difficult and complex, and therefore, the recruitment process was timeconsuming (Banks et al., 2002; Frank, Tatum, \& Tucker, 1999). To find additional interviewees, we also used a snowball approach within our project partner's wider network.

\section{Sample and data collection}

To represent the broad range of young (adult) carers, we sought a heterogeneous sample with regard to their age, gender, and language region. We conducted 30 semi-structured interviews with 16 young carers aged 10 to 17 and 14 young adult carers aged 18 to 25 . The interviews were conducted in seven cantons in either Swiss German or French.

After the interview partners had received our interview invitations through our gatekeepers who passed it on to potential participants, the interview partners contacted us, either by phone or email. We then sent them detailed information about the study, an informed consent form, and, in case participants were under 14, an additional informed consent form for the parent to allow participation in the study. These documents were sent as paper copies by mail. The interviewees were informed that the purpose of the study was to learn more about young carers and young adult carers in Switzerland in order to raise awareness of the topic and to establish support structures. Before the interviews started, the purpose of the study was again explained to the interviewees by the interviewer. The interviewees were then asked to sign the informed consent form.

We also asked the interviewees where they would like to have the interview. In 15 cases, the interviews took place in the young persons' homes, one interview took place in our office, 6 in the office of our French-speaking colleagues, 6 in a café, 1 in a school, and 1 at an interviewee's work place. Four interviews were conducted with parents present because the children preferred that. 
We used a semi-structured questionnaire with open questions. Using the approach of Kruse (2015), we developed a questionnaire that allowed for a high level of openness combined with a thematic focus on our topics of interest: we focused on a) the pathways into care (using the question "in addition to your school/education, you care for a sick family member. Could you please tell me how did this come about?"), b) the nature and intensity of the provided care ("Could you tell me what you do for [your family member]?"), c) living circumstances of the young (adult) carer ("What does a typical day in your life look like at home and in school/education"), d) the family life ("How would you describe living together in your family?") and further care arrangements ("How do you organise the care for [your family member] with the other persons involved [in providing care]?). Additionally, we asked a number of sociodemographic questions concerning the interviewees' gender, language region, the family member they supported, the impairment of the family member they cared for (for example, whether they had physical, mental, or other problems), the family situation (whether they were part of a single or two parent family, or if they lived apart from the family), the number of siblings and family background (for example, whether they were migrants or refugees). All the interviews were digitally recorded and fully transcribed.

\section{Data analysis}

Our study aimed to explore the personal experiences and perceptions of young carers; we therefore chose a grounded theory approach (Charmaz, 1990; Strauss \& Corbin, 1998). Grounded theory (GT) is an inductive methodology based on the purpose of generating a theory that emerges from the collected data itself (Berg \& Milmeister, 2008; Strauss \& Corbin, 1990).

In the beginning of the analysis process, the entire research team read the interview transcripts. Then, CJ and MF performed open, axial and selective coding, wrote memos during the analysis and discussed the interpretations of selected interview passages frequently within the entire research team. We then organised our data into thematic categories.

Data collection and analysis were conducted continuously and consistently in keeping with a GT approach. The transcripts were analysed using the software MAXQDA 12 (MAXQDA, 1989 - 2017). 


\section{Findings}

From our analysis, three themes emerged: "nature and intensity of caring roles", "ways into care" and "communication about the caring role". They are presented below after a short description of the socio-demographic characteristics of the study participants. The interviewees stressed the importance of communication for their caring roles.

\section{Socio-demographic characteristics of the participants}

Of the 30 young people interviewed, 29 matched our criteria for a young carer or young adult carer and one person was excluded because he had no caring role; 15 interviewees were under 18 (11 female and 4 male), and 14 were young adult carers (13 female and 1 male) aged 18 to 25 . The number of female participants exceeded males almost fourfold (24 females compared with 5 males).

Fifteen participants cared for a family member with a physical impairment, and 10 cared for one with a mental health problem. Over half of the participants (16/29) provided care for their mothers. Among those 16, there was only one male young carer. Four young adult carers who described themselves as a main carer - meaning they are mainly responsible for the care provision, looked after a mother with a mental health problem. Additionally, if they had (younger) siblings, they took on responsibility for them as well. Only one young carer (female) was a main carer for her father who suffered from multiple physical impairments. Four of the participants did not live with their family: two females aged 16 and 17 lived in a boarding school close to their home during the week in order to focus on their education; two female young adult carers had moved out to live with their partners. Three interviewees aged 10 to 17 and two aged 18 to 25 were from migrant families.

These data are summarised in Table 2.

Table 2

Little information on their socio-economic circumstances was given by the interviewees. The group of young carers under the age of 18 were seldom aware of the financial situation of their family. Young 
adult carers, on the contrary, brought up the topic of family finances if they felt financial difficulties or restrictions. One female had taken on work in addition to her vocational training in order to support her family with extra income.

\section{Nature and intensity of caring roles}

Our findings show that young people with caring responsibilities engage in a wide range of caring activities, such as providing emotional support, personal care, sibling care, domestic and household tasks, dealing with financial issues and coordinating with professionals from healthcare, social welfare and other authorities. A 16-year-old young carer with a mentally and physically impaired older brother described her caring role as follows:

'When I was five, I quickly learned to deal with this [his impairment]. I fed him, I learned from a young age how to change his nappies, dress him and do the caring, even shower him, if necessary.' (Interviewee (I) 14, 25)

A female young adult carer, who lived together with her mother who had mental health problems and two brothers, illustrated her daily tasks:

'[...] I had to take over in the household. I had to cook for my two brothers. We got home from school and there was no food. So, I had to buy groceries and prepare lunch. As soon as we finished eating, we had to go back to school.' $(13,5)$

With no other adult person available, she took on additional jobs after school to support their family financially:

'I had to figure out how to pay our bills. So, I took on a job to get us going somehow [...]' (I $3,89)$

The intensity of the support given by young carers ranged from part-time engagement to full responsibility over a long time period and varied depending on the mental and physical state of the 
person cared for.

`I was about four or five. I was alone with him [brother, three years older] for a few hours from an early age. My mother had to go to work, as my parents were divorced.' $(14,23)$

If, through separation or death, the main adult carer was absent, responsibility and taking charge of the family situation was often experienced as a burden. Some statements showed the difficulties of coping with school, vocational training and higher education whilst having a caring role:

'The difficult part was to perform well in school and also manage somehow to fit everything else in.' (I 5, 72)

\section{Ways into care}

The interviewees described a number of different ways in which they became carers. These can be summarised in three categories: suddenly, gradually and 'normal'.

\section{Suddenly}

Several young carers described an abrupt start into their caring role following a significant change in their family structure. In our interviews, this happened through the birth of an impaired or ill sibling, through the illness of a single parent or through the separation or death of the former main carer. Often, parents were not available at home anymore because, for example, they spent most of their time at the hospital with the ill sibling or had to start working again:

'[...] and then, suddenly, from one day to the other, she [mother] did not do anything anymore.' ( 515,6$)$

Here, a young adult carer described the situation when her father left her mentally ill mother and the three children: 
'It started when my father moved out. It was as if our world would collapse, my foundations, my family... exploded.' (I 266, 285)

\section{Gradually}

Young people tend to take on greater responsibility within the family as they become older. This relation to age became especially apparent in four interviews with female young adult carers living with their mentally ill mothers. In all the interviews conducted, it was difficult for young carers with a gradual progression into caring to name a particular point of time when they started their caring responsibility:

'I did take care partially of my mum [...], and besides that I did all the household tasks. I was never aware of this. [...] for me, this was part of my life.' (I 10 82)

'Normal'

Most of the interviewees described their way into care as a 'normal' process within their family life.

They did not realise how taking on significant caring responsibility or filling in gaps for absent adults was putting them in a new position in the family structure. This lack of recognition was often due to a lack of awareness and knowledge around the issue of young carers:

'It is just normal. It has always been like this.' $(I 11,2)$

Two young women living with their mentally ill mothers described the moment of realising that their lives differed from those of their friends:

'[...] I was invited to a birthday party for a friend from school. [...] And there I saw how different their family life was and how they treat each other. Then, I began to realise what was not going well at home. Before that, everything was just normal to me.' $(10,18)$

In contrast, young adult carers who took on their caring role late in their adolescence were aware of the amount of responsibility they shouldered:

'It was hard, we had to change the normality [of life].' (I 26, 482) 


\section{Communication about the caring situation}

Throughout all the interviews conducted, the theme of communication about the care situation emerged. This new key category ranged within a spectrum from 'non-communication' or 'silence' to 'information and coordination hub' with numerous nuances. These different aspects of talking about their situation took place in various realms. Here, we illustrate communication within the (core) family, the extended family (e.g., grandparents, aunts, uncles), and with professionals and peers.

\section{Communication within the family}

When young people talked about their situation outside the privacy of home, it was mainly in agreement with the person they cared for or other close family members. A female young adult who was caring for a mother with mental health problems explained:

'Our dad has always told us everything. He always said what was going on with mum.

Because most of the time, mum could not talk to us anymore.' $(I 15,16)$

Some families, on the contrary, would not talk about a parent's illness at all. Here, a young adult carer mentioned retrospectively:

'It made me extremely sad and thoughtful and [...] scared because I could not name the problem.[...] No one has ever talked to me about it.' (I 10, 20)

When there is a lack of communication, for example, when those who are ill decide not to talk to their children about their illness, disturbing situations can occur. A 10-year-old girl with a severely depressive mother who had made several suicide attempts described the moment when she learned from her best friend about her mother's illness. When chatting along, her friend informed her:

'I know something about your mum you don't.' (I 22, 153)

\section{Communication with the extended family}

When communicating about the illness, several young carers reported that they were often contacted 
by other family members who wanted to know about the current state of health of the person they looked after. One young carer told us:

'I started writing a blog for them [family members] about how mum was doing [...]. And even though we told them, we did not want any telephone calls, we do not want to explain the same thing a thousand times, they disregarded our wish and even reproaches were addressed to us.' (I 6, 31)

When starting to act as a communication and coordinating hub within and outside the family, this young woman viewed this experience as time-intense and stressful:

'Explaining the same thing a thousand times - that really hurts.' $(16,81)$

Another female young carer looking after her schizophrenic mother and her younger sibling alone described a similar situation. She preferred to deal with her situation alone instead of asking for help out of fear that she would have to talk about her difficulties:

'[...]. I thought I cannot call them up and ask them to help me with the laundry. Because then, they want to talk to me. But I can't, or I don't want to talk to anybody right now because I don't see anything else except my situation right now.' $(19,50)$

In other cases, the use of social media to stay in contact with the care network was successful. Looking after her father who had Alzheimer's disease, this young adult carer described her communication with her extended family and close health care professionals as follows:

'Well, I help with the coordination, too, with daily structures, medical appointments and so on. We set up a WhatsApp chat with all the nurses and people and friends who are involved in looking after him, just in case someone needs help.' (I 23, 33)

\section{Communication with professionals}

Talking to professionals was often seen as difficult in many ways. In particular, getting into contact with health care professionals in hospitals seemed to be challenging when young carers or young adult carers 
were the main carer:

'It is very difficult to get into or stay in contact with nurses or doctors who take care of my mother. I don't think they do it deliberately. I think it is the profession. They have to take care of the patient, but [...] we have to live with her.' $(126,68)$

Information was often withheld by health care personnel due to a perceived need for confidentiality. Two young adult female main carers highlighted their difficulties in communicating and engaging with medical staff:

'Because no one has informed me, I was given zero information! And when I wanted to ask them they said 'Sorry, I can't tell you, obligation of confidentiality. Your [schizophrenic] mother has to give permission first. [...] I was so frustrated! I did not get any information but was the one who organises everything. [...]' $(19,132)$

When communication was understood as receiving information, some young adult carers found ways in which to access the necessary information when neither the professionals nor the care-receiving family member provided it:

'I had been searching on the internet a lot and wanted to know what this illness was. I have done this very often, as I simply never got any information from my Mum.' (I 6, 221)

In addition to communicating with health care professionals, talking to relevant persons in education or vocational training also emerged as an important topic. A young carer looking after her grandparents who lived in the same house told us:

'I have been too tired. Sometimes I would fall asleep during class. However, the teachers didn't know. I did not go up to them and say 'My grandparents are sick, I was not able to do my homework'. [...] But, sometimes, I wished they had known about it.' $(17,63)$

A female young carer in vocational training decided to inform her boss about her mother's mental illness quite frankly: 
'Well, I went up to see my boss and I told her right away that my mother suffers from schizophrenia. And that it could happen any time that she calls her and tries to say bad things about me.'(I 16, 136)

When talking with professionals from social services, a number of young adult carers who managed their single parents' finances and state benefits were very cautious:

'Well, from a legal point of view, you lose when you go and ask for help. Depending on whom you talk to, they will inform the authorities right away. So, one is better off by just forgetting about it and go on fighting.' $(19,30)$

\section{Communication with peers}

Talking about an ill family member with friends in school or vocational training showed positive as well as negative impacts on the young carers' relationship with their peers. A female young carer looking after her severely impaired younger brother reported:

'They told me several times 'Hey, I think it is amazing what you are doing.' It is not the case that they don't know, or they are not interested at all. [...] They also tell me 'I could never do what you are doing!' $(17,57)$

Another young carer described how her family who had a disabled boy tried to show their situation to other schoolchildren:

'When I was in my last year of primary school we invited my class to come home in order to show them how he lives with all the assistive equipment. Well, then their understanding was a bit higher, but, actually, still not really.' (I 20, 37)

Several young carers described that even if friends from school knew about their family situation, they 
were often unaware of the amount of time young carers spent caring for an ill or impaired family member.

'Well, they asked me 'Will you come out with us after dinner?' I told them 'No, I can't. I have to care and look after my brother.' (I 20 33)

In cases when the family illness was something the young carers did not want to talk about, they avoided social interaction with friends outside of school:

‘I never spoke about my family situation. They asked me 'Can we come home to your place?' I never invited them home because I was ashamed of our household because I was ashamed of my mother. I was so ashamed.' $(13,67)$

When having other young carers as friends, the interviewees valued their exchange and felt supported by their peers:

'It was not about, now we are two'. It was more about the sensation of having someone to talk to who understands me, who knows what I am going through. [...].' $(19,14)$

\section{Discussion}

Our study showed that young persons with caring duties are a reality in Switzerland too. When we looked for them, we could find girls, boys, young women and young men. It was striking that we spotted so many more female carers than males (ratio $24: 5$ ). Since our study followed a qualitative design, this gender difference is not necessarily representative of the population of young carers in Switzerland as a whole but could point towards a gender bias. This issue needs to be explored in future research. In most cases in our study, young persons cared for their mothers (16/29), followed by care for siblings (9), fathers (3) and grandparents (1). The majority of the care recipients had physical impairments (15), followed by those with mental health problems (10) and addiction (1). In three cases, there was no indication as to the condition of the care recipient. We also showed that young carers are present not 
only in single-parent families (12) but also in families with two parents (13). These findings are in line with international research (McDonald, Cumming, \& Dew, 2009; Moore \& McArthur, 2007; Nagl-Cupal, Daniel, Kainbacher, Koller, \& Mayer, 2012; Smyth, Blaxland, \& Cass, 2011; Stamatopoulos, 2015) and show the broad circumstances of young carers and young adult carers.

We found very different types of caring tasks among our interviewees: they provided personal care (such as changing nappies, feeding) or sibling care (e.g., watching over siblings); very often, they took over domestic (such as providing meals) and household tasks (e.g., buying groceries), usually with a growing number of responsibilities over time. Dealing with monetary issues, for example, by supporting the family financially by taking on paid work was also mentioned, particularly by young adult carers. The tasks young carers and young adult carers took on depended on the nature of the illness or impairment of the person receiving care and on the availability of other carers within the family. The intensity of the caring role varied from part-time to full-time responsibility. It was often higher when no other adult was available, and the interviewees were the main carers. Our findings presented here show a similar profile of caring tasks and responsibilities provided by children, adolescents and young adults already described in other studies in other countries (Becker, 1995, 2007; Becker, Aldridge, \& Dearden, 1998; Carers Association of Australia, 2002; Dearden \& Becker, 1998, 2004; Evans, 2010; Gays, 2000; Moore, 2005; Morrow, 2005; Nagl-Cupal et al., 2012; Schnepp \& Metzing, 2005). This underlines the comparability of the circumstances of young carers in Switzerland with those in other countries.

Young carers in our study highlighted the impact of the caring responsibilities on their school and vocational training. They often had trouble concentrating and difficulties in focussing on their social life due to worrying about their ill or disabled family member. These issues have also been described by other researchers (Banks et al., 2001; Frank et al., 1999; Moore, 2005; Moore, McArthur, \& Morrow, 2009).

Regarding the different pathways into care, we can divide our results into 'suddenly', 'gradually' and 'normal', referring to young carers' and young adult carers' own wording and depending on the type of illness of the person in need and the situation that led them to take on the caring role (Becker et al., 1998; Becker \& Becker, 2008). Mostly, children, adolescents and young adults grew gradually into their caring role and considered it normal (Smyth et al., 2011). Only in cases when it came from a sudden change in their lives and changes in their family structure did they realise the change. Notably, when the 
ways into care are described as 'gradually' or 'normal', the challenges for providing appropriate support become apparent. Processes are then hard to spot by professionals or other family members and are hardly recognised by the young carers themselves (Smyth et al., 2011). Based on our findings, we would like to stress the importance of communication during and around caring situations. This issue played a significant role for all interviewees and has so far not been thoroughly addressed by national or international research on young carers. In our study, we identified communication within the family, with the extended family, with professionals and with peers as important themes. In all of these arrays, we found scopes ranging from adequate communication to total silence. Communication within the family included the core family and was usually considered very personal and private. Most of the interviewees discussed the illness of the care recipient solely within the family. Within the family, young carers and young adult carers described a spectrum from discussing everything within the inner family circle, and even joking about the illness, to tabooing the subject and turning it into non-communication. Importantly, when families decided not to talk about the care situation, several young carers in our study struggled with this.

In the subcategory 'communication with the extended family', we also found a broad spectrum of how communication can be functional or dysfunctional. Several young carers described the exhaustion they experienced. This is consistent with the work of Rose and Cohen (2010) who emphasised the lack of awareness and insight of those who do not recognise young people's caring roles. However, we also found examples where communication with the wider family network worked well, and where the use of social media indeed facilitated that communication.

Communication with professionals was often experienced as a challenge by our interviewees. This was especially the case when they were the main carer in the family. They described situations in which they were simply overlooked by experts from healthcare or social services. This generally did not happen because of malicious intent by professionals but rather due to a lack of awareness about young carers and their roles and responsibilities (Leu, Frech, \& Jung, 2017, under review). In our study, it was often the young adult carers who found their own ways in which to find the necessary information. For younger carers, this seemed more challenging. How to talk or not to talk with professionals from other fields, such as education/vocational training or social services, was also an issue that emerged from our findings and this should be addressed more deeply in future studies. Young carers and young adult 
carers are a vulnerable group that needs special support due to their caring role. When professionals who are supposed to provide support are instead perceived as a threat, it shows that communication structures are not yet well established. More awareness and a sharpened view from the professionals would be helpful in order to allow young carers to open up and ask for support. The research team will address this issue in a national large-scale online survey for professionals from the health care, education and social service sector.

Concerning peer communication, we found young carers who were open about an ill or impaired family member and others who tried to hide it completely. Even when discussing the matter openly, several reported that their peers could not truly understand what the young carers were doing (Rose \& Cohen, 2010). It was only when talking to other carers that they described the feeling of being understood. Young carer groups or projects enable such young people to meet others with similar circumstances and family situations and promote peer support. In conclusion, the theme of communication adds a new dimension to young carer research. It highlights the importance of communication in order to avert isolation and enable access to support through recognition and information. When designing and promoting specific interventions and strategies, our findings demonstrate the significance of communication in order to initiate and coordinate target-oriented support. There are good experiences of such support from other countries, and it should be a priority to establish similar groups in Switzerland. As Leu and Becker have reported, one of the key factors that influence the extent and nature of policy responses is the presence of a reliable country-specific research base (2016). Therefore, the findings from this study provide the first national data with regard to young carers. In 2014 , the Swiss Federal Council launched an Action Plan consisting of different fields of action to improve the situation for all carers (Swiss Federal Council 2014). Our planned future research, including quantitative and mixed methods research, will provide information on the specific needs of young carers and will, therefore, support the new Actin Plan. Supporting the person receiving care will also benefit the young carer and the young adult carer; on the other hand, supporting young carers will contribute to the well-being of the care recipient and the whole family. 


\section{References}

Banks, P., Cogan, N., Deeley, S., Hill, M., Riddell, S., \& Tisdall, K. (2001). Seeing the Invisible Children and Young People Affected by Disability. Disability \& Society, 16(6), 797-814. doi:10.1080/09687590120083967

Banks, P., Cogan, N., Riddell, S., Deeley, S., Hill, M., \& Tisdall, K. (2002). Does the covert nature of caring prohibit the development of effective services for young carers? British Journal of Guidance \& Counselling, 30(3), 229-246. doi:10.1080/030698802100002281

Becker, F., \& Becker, S. (2008). Young adult carers in the UK: Experiences, needs and services for carers aged 16-24. London: The Princess Royal Trust for Carers.

Becker, S., Aldridge, J., \& Dearden, C. (1998). Young Carers and Their Families. Oxford: Blackwell Science.

Becker, S. (Ed.). (1995). Young Carers in Europe: An Exploratory Cross-National Study in Britain, France, Sweden and Germany. UK: Loughborough University, Young Carers Research Group.

Becker, S. (2007). Global Perspectives on Children's Unpaid Caregiving in the Family: Research and Policy on 'Young Carers' in the UK, Australia, the USA and SubSaharan Africa. Global Social Policy, 7(1), 23-50. doi:10.1177/1468018107073892

Becker, S., \& Leu, A. (2014). Young Carers. In H. Montgomery (Ed.), Oxford Bibliographies in Childhood Studies . New York: Oxford University Press.

Berg, C., \& Milmeister, M. (2008). Im Dialog mit den Daten das eigene Erzählen der Geschichte finden. Über die Kodierverfahren der Grounded-Theory-Methodologie. FQS Forum: Qualitative Sozialforschung, 9(2, Art. 13). 
Carers Association of Australia (Ed.). (2002). Young Carers Research Project: Final Report. Canberra, Australia: Commonwealth Department of Family and Community Services.

Cass, B., Smyth, C., Hill, T., Blaxland, M., \& Hamilton, M. (2009). Young carers in Australia: Understanding the advantages and disadvantages of their care giving. Social policy research paper / Dept. of Families, Housing, Community Services and Indigenous Affairs: no. 38. Canberra, ACT: Dept. of Families, Housing, Community Services and Indigenous Affairs.

Charmaz, K. (1990). 'Discovering' chronic illness: Using grounded theory. Social Science \& Medicine, 30(11), 161-1172. doi:10.1016/0277-9536(90)90256-R

Dearden, C., \& Becker, S. (1998). Young Carers in the United Kingdom: A Profile. London.

Dearden, C., \& Becker, S. (2004). Young Carers in the UK: The 2004 Report. London.

Early, L., \& Cushway, D. (2002). The parentified child. Clinical Child Psychology and Psychiatry, 7(2), 163-178.

Evans, R. (2010). Children's Caring Roles and Responsibilities within the Family in Africa. Geography Compass, 4(10), 1477-1496.

Fives, A., Kennan, D., Canavan, J., \& Brady, B. (2013). Why we still need the term 'Young Carer': Findings from an Exploratory Study of Young Carers in Ireland. Critical Social Work, 14(1), 49-61.

Frank, J. (1995). Couldn't Care More: A Study of Young Carers and Their Needs. London: Children's Society.

Frank, J., Tatum, C., \& Tucker, S. (1999). On Small Shoulders: Learning from the Experiences of Former Carers. London: Children's Society. 
Gays, M. (2000). Getting It Right for Young Carers in the ACT. Paper delivered at the 7th Australian Institute of Family Studies Conference, "Family Futures: Issues in Research and Policy". Sydney.

Hill, T., Smyth, C., Thomson, C., \& Cass, B. (2009). Young Carers: Their

Characteristics and Geographical Distribution. Canberra, Australia: Social Policy Research Centre.

Knowles, S., Combs, R., Kirk, S., Griffiths, M., Patel, N., \& Sanders, C. (2016). Hidden caring, hidden carers? Exploring the experience of carers for people with long-term conditions. Health \& Social Care in the Community, 24(2), 203-213.

doi:10.1111/hsc.12207

Leu, A., \& Becker, S. (2016). A cross-national and comparative classification of incountry awareness and policy responses to 'young carers'. Journal of Youth Studies, 20(6), 750-762. doi:10.1080/13676261.2016.1260698

Leu, A., \& Frech, M. (2015a). Encore méconnus, mais pas oubliés: Enfants, adolescents et jeunes adultes aidants. Krankenpflege - Soins infirmiers, 108(8), 56-58.

Leu, A., \& Frech, M. (2015b). Verborgene Kinder sichtbar machen. Pflegerecht, 4(4), $229-233$.

Leu, A., Frech, M., \& Jung, C. (2017, under review). "You don't look for it" - a study of Swiss Professionals’ Awareness of Young Carers and their Support Needs.

Leu, A., Jung, C., \& Frech, M. (2016a). Erwachsene, Jugendliche und junge Erwachsene als pflegende Angehörige in der Schweiz. Paediatrica, 27(2), 1-3.

Leu, A., Jung, C., \& Frech, M. (2016b). Kinder und Jugendliche sind besonders schutzbedürftig: Kinder, Jugendliche und junge Erwachsene als pflegende Angehörige in der Schweiz. Clinicum, (4), 39-41. 
Leu, A., Jung, C., \& Frech, M. (2017). Junge Menschen als pflegende Angehörige. Schulblatt AG/SO, (5), 40-41.

MAXQDA. (1989 - 2017). Software für qualitative Datenanalyse. VERBI Software. Consult. Sozialforschung GmbH. Berlin, Deutschland.

McDonald, J., Cumming, J., \& Dew, K. (2009). An exploratory study of young carers and their families in New Zealand. Kotuitui: New Zealand Journal of Social Sciences Online, 4(2), 115-129. doi:10.1080/1177083X.2009.9522448

Moore, T. (2005). Young carers and education: Identifying the barriers to satisfactory education for young carers. Youth Studies Australia, 24(4), 50-55.

Moore, T., \& McArthur, M. (2007). We're all in it together: supporting young carers and their families in Australia. Health \& Social Care in the Community, 15(6), 561568. doi:10.1111/j.1365-2524.2007.00719.x

Moore, T., McArthur, M., \& Morrow, R. (2009). Attendance, Achievement and Participation: Young Carers' Experiences of School in Australia. Australian Journal of Education, 53(1), 5-18. doi:10.1177/000494410905300102

Moore, T., Morrow, R., McArthur, M., Noble-Carr, D., \& Gray, J. (2006). Reading, Writing and Responsibility: Young Carers and Education. Canberra, ACT: Institute of Child Protection Studies.

Morrow, R. (2005). A profile of known young carers and identification and snapshot of the ones who are hidden. Curtin University of Technology, Perth.

Nagl-Cupal, M., Daniel, M., Kainbacher, M., Koller, M., \& Mayer, H. (2012). Kinder und Jugendliche als pflegende Angehörige: Einsicht in die Situation gegenwärtiger und ehemaliger pflegender Kinder in Österreich. Wien. 
Rose, H. D., \& Cohen, K. (2010). The experiences of young carers: a meta-synthesis of qualitative findings. Journal of Youth Studies, 13(4), 473-487. doi:10.1080/13676261003801739

Schnepp, W., \& Metzing, S. (2005). Kinder und Jugendliche als pflegende Angehörige: Eine Untersuchung zu Bedeutung und Konstruktion familialer Pflege, welche von Kindern und Jugendlichen erbracht wird. Pflege \& Gesellschaft, 10(1), 61-62.

Smyth, C., Blaxland, M., \& Cass, B. (2011). 'So that's how I found out I was a young carer and that I actually had been a carer most of my life'. Identifying and supporting hidden young carers. Journal of Youth Studies, 14(2), 145-160.

doi:10.1080/13676261.2010.506524

Stamatopoulos, V. (2015). One million and counting: the hidden army of young carers in Canada. Journal of Youth Studies, 18(6), 809-822. doi:10.1080/13676261.2014.992329

Strauss, A., \& Corbin, J. (1990). Basics of qualitative research: Grounded Theory procedures and techniques. Newbury Park, CA: Sage.

Strauss, A., \& Corbin, J. (1998). Basics of Qualitative Research: Techniques and Procedures for Developing Grounded Theory. Second Edition: Sage Publications.

Swiss Federal Council. (2014). Unterstützung für betreuende und pflegende Angehörige Situationsanalyse und Handlungsbedarf für die Schweiz. Bern: Department of Health. 